\title{
S-I
}

Tweezing-Adsorptive Bubble Separation - A Novel Analytical Method for the Selective and High Enrichment of Metalloenzymes

Birte M. Gerken, ${ }^{*}$ Carsten Wattenbach, ${ }^{*}$ Diana Linke, ${ }^{* *}$ Holger Zorn, ${ }^{* *}$ Ralf G. Berger, ${ }^{* *}$ and Harun Parlar $^{*} \S$

*Technical University of Munich, Department of Chemical-Technical Analysis and Chemical Food Technology; Research Center Weihenstephan for Brewing and Food Quality, Weihenstephaner Steig 23, D-85354 Freising-Weihenstephan (Germany). **University of Hannover, Institute of Food Chemistry, Wunstorfer Str. 14, D-30453 Hannover (Germany)

\section{RECEIVED DATE}

${ }^{\S}$ Corresponding author; E-mail: parlar@wzw.tum.de, phone: +49 (0)8161 71-3283, fax: +49 (0)8161 $71-4418$

Description. Therein, a diagram of the Adsorptive Bubble Separation apparatus is provided as well as the towards the optimum varied process parameters and further graphical material for more information about how the chelation of laccase and HPOX takes place. 


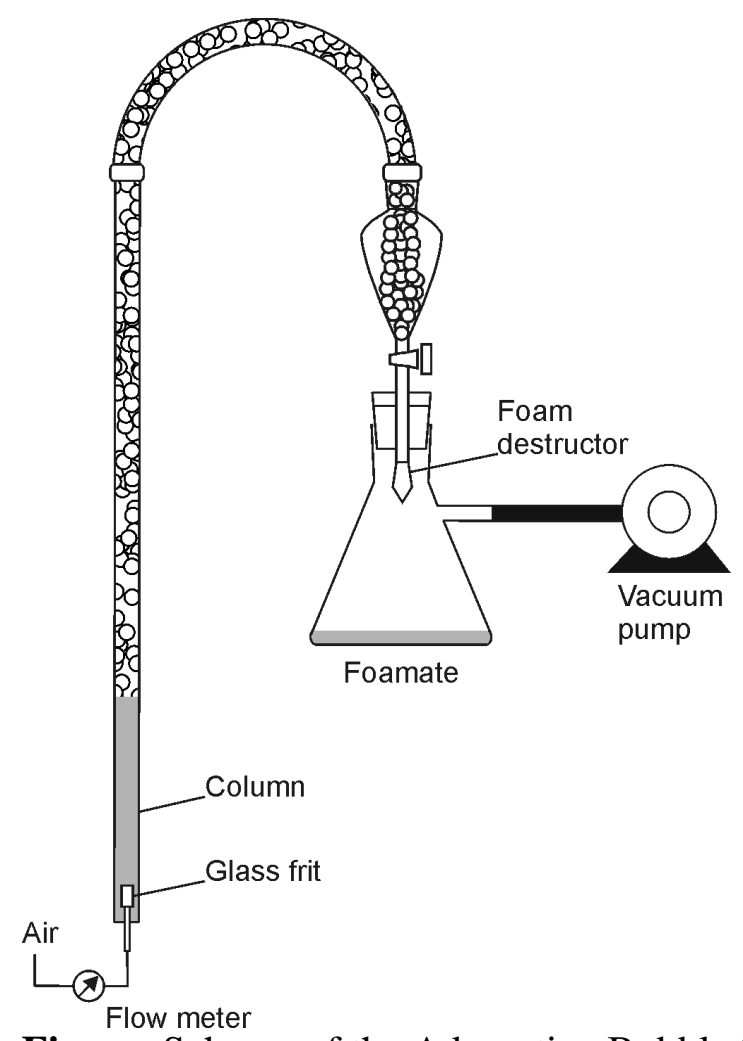

Figure. Scheme of the Adsorptive Bubble Separation apparatus.

Table. Optimum Adsorptive Bubble Separation Parameters.

\begin{tabular}{|l|c|c|c|c|}
\hline Enzym & Chelator $\left(\mathrm{mg} \mathrm{mL}^{-1} ;\right.$ initial) & $\mathrm{pH}$ & Gas flow rate $\left(\mathrm{mL} \mathrm{min}^{-1}\right)$ & Foaming time $(\mathrm{min})$ \\
\hline Laccase $^{a}$ & - & 5.5 & 10 & 10 \\
\hline Laccase $^{a}$ & ADA (55.0) & 5.5 & 10 & 10 \\
\hline Laccase & ADA-C8 (3.0) & 10 & 1 & 30 \\
\hline Laccase & ADA-C8 (3.0) & 10 & 1 & 30 \\
\hline HPOX & ADA-C8 (65.0) & 10 & 1 & 30 \\
\hline HPOX & ADA-C8 $(65.0)^{c}$ & 10 & 1 & \\
\hline
\end{tabular}

${ }^{a}$ Applied with CTAB $\left(0.4 \mathrm{mg} \mathrm{mL}^{-1}\right) .{ }^{b}$ chelated with $\mathrm{CuSO}_{4} \times 5 \mathrm{H}_{2} \mathrm{O}\left(2.5 \mathrm{mg} \mathrm{mL}^{-1}\right) .{ }^{c}$ chelated with $\mathrm{FeCl}_{3}\left(59.0 \mathrm{mg} \mathrm{mL}^{-1}\right)$.

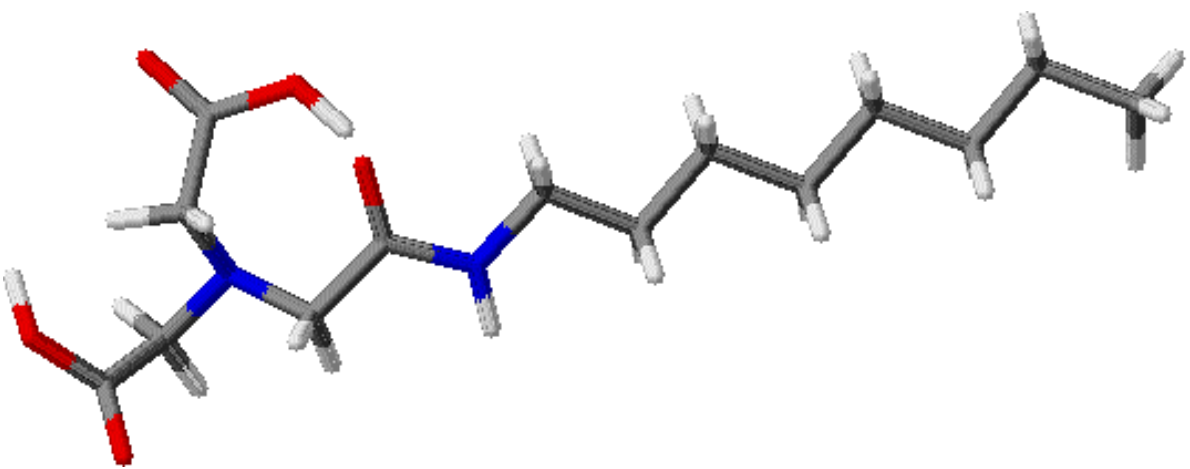

Figure: ADA-C8; carbon: black, hydrogen: white, nitrogen: blue, oxygen: red. 
Oxidoreductases, their active centers, and the shielding of the active centers:

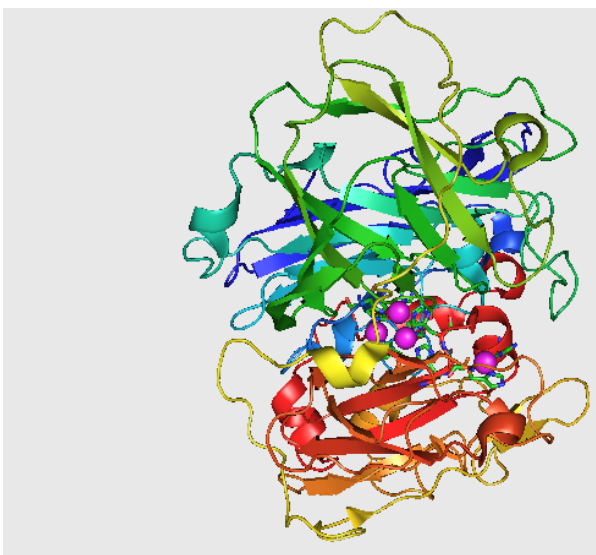

Structure of laccase (1gyc.pdb1)

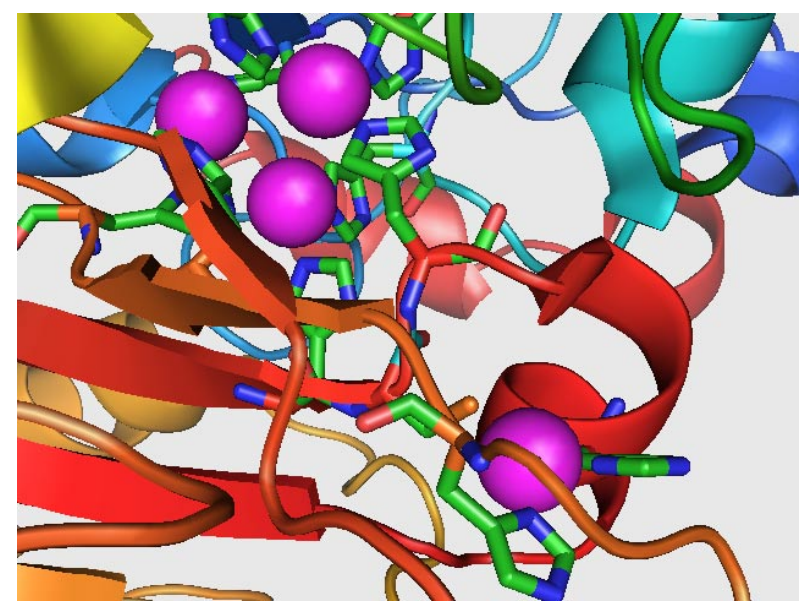

Active center of laccase (1 gyc.pdb1)

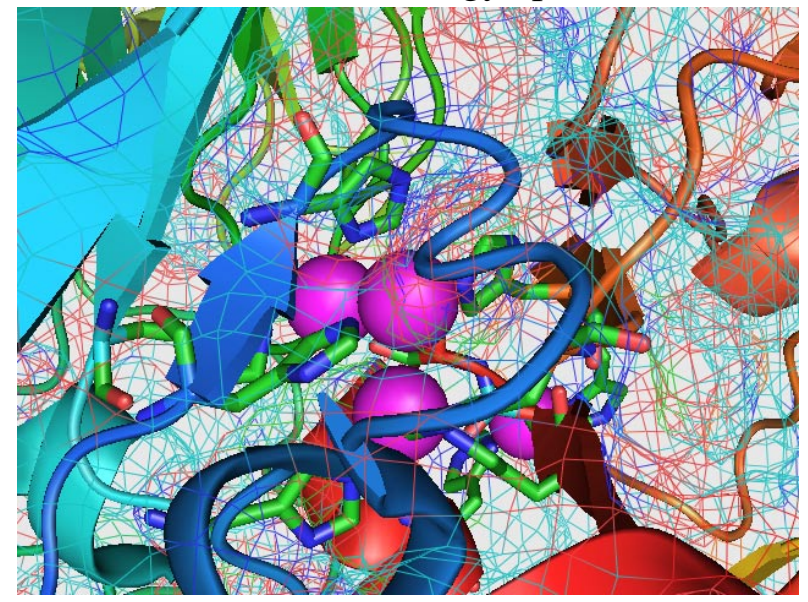

Shielding of the type- 2 and type- 3 copper center of laccase (1gyc.pdb1)

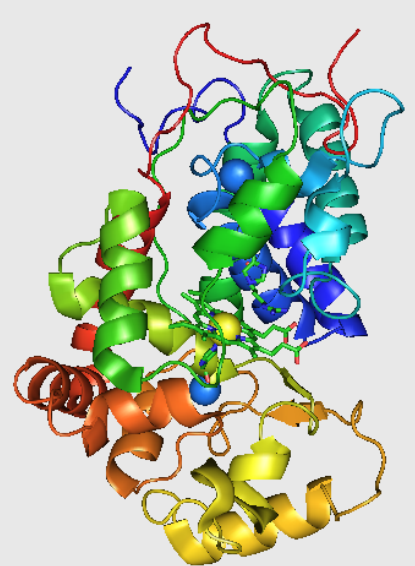

Structure of HPOX (1gwo.pdb1)

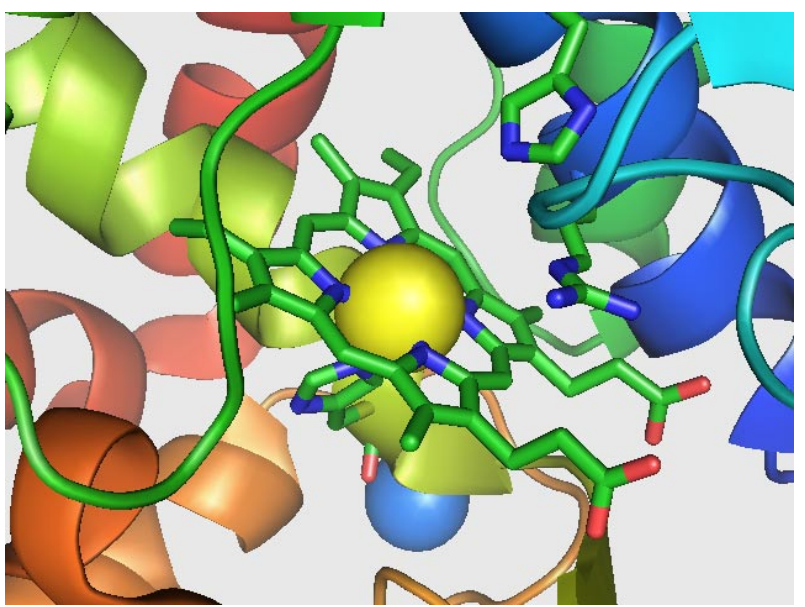

Active center of HPOX (1gwo.pdb1)

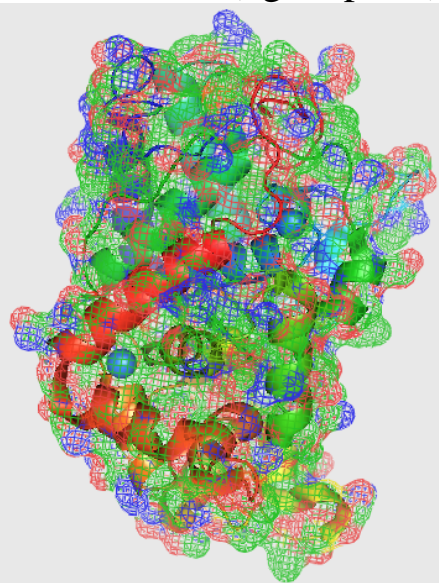

Shielding of $\mathrm{Ca}^{2+}$ (blue spheres) of HPOX (1gwo.pdb1) 